* Forthcoming in Synthese.

\title{
How Can Necessary Facts Call for Explanation?
}

\section{Dan Baras}

\begin{abstract}
While there has been much discussion about what makes some mathematical proofs more explanatory than others, and what are mathematical coincidences, in this article I explore the distinct phenomenon of mathematical facts that call for explanation. The existence of mathematical facts that call for explanation stands in tension with virtually all existing accounts of "calling for explanation", which imply that necessary facts cannot call for explanation. In this paper I explore what theoretical revisions are needed in order to accommodate this phenomenon. One of the important upshots is that, contrary to the current consensus, low prior probability is not a necessary condition for calling for explanation. In the final section I explain how the results of this inquiry help us make progress in assessing Hartry Field's style of reliability argument against mathematical Platonism and against robust realism in other domains of necessary facts, such as ethics.
\end{abstract}

Keywords: Calling for Explanation; Strikingness; Necessary Facts; Probability; Logical Omniscience; Philosophy of Mathematics

\section{The dilemma}

Regarding some facts we judge that they call for explanation, while for others we do not. Suppose you take an ordinary looking coin and toss it hundreds of times. Suppose it lands 
HTHTHTHTHT... (H=heads; T=tails) and continues in this pattern every single toss. Such an occurrence would no doubt call for explanation. On the other hand, if the result were a messy, insignificant sequences of $\mathrm{H}$ and $\mathrm{T}$, the occurrence would not call for explanation. Another example. Suppose you take a chimpanzee and seat it by a typewriter. The chimpanzee, surprisingly, starts typing at great speed. Suppose it turns out that the chimpanzee was typing predictions of many future events. And suppose that every single prediction is verified. Such an occurrence would surely call for explanation. Whereas, if it turned out that the chimpanzee was typing gibberish, it would not call for explanation. Any number of examples can be given to illustrate this distinction. ${ }^{1}$

Many authors have noticed a salient feature of the typical examples that appear in the literature: They are all occurrences with very low prior probability. Therefore, it is commonly believed that a necessary condition for calling for explanation is a low prior probability. Thus, Paul Horwich says that "the improbability of an event is not sufficient - but it does seem necessary (Horwich, 1982, p. 101)". George Schlesinger says that "all extraordinary events are highly improbable" (Schlesinger, 1991, p. 95). Neil Manson and Michael Thrush say that "[i]mprobability...seems to be ... a necessary condition..." (Manson \& Thrush, 2003, p. 80). David Harker says that "[i]t is necessary that we judge the event improbable" (Harker, 2012, p. 253). And Roger White says that "extremely improbable...is part of what makes something call for explanation" (White, 2018, p. 31). ${ }^{2}$ Andreas Mogensen goes as far as to claim that "no one disputes the necessity of

\footnotetext{
${ }^{1}$ For more examples, see Leslie (1989, pp. 8-19), White (2005, p. 3) and White (2018).

${ }^{2}$ Some authors imply that there is a close connection between calling for explanation and improbability, but do not state explicitly that they view improbability as a necessary condition. Examples include Smolin (1997, p. 45) and Price (2002, p. 115).
} 
this condition" (Mogensen, n.d., n. 24). Now the literature on what calls for explanation, not to be confused with the distinct issue of what explanations are, is relatively small and coarse. Any one of these quotes is drawn from a context that requires interpretive work, that I cannot get into here. $^{3}$ For our purposes, it is sufficient to note that the assumption that low prior probability is necessary for calling for explanation is a prevalent one, and very tempting in light of paradigmatic examples of contingent facts that call for explanation. One of the insights of this article will be that this temptation should be resisted, but let us not jump ahead.

Mathematical results can give rise to similar calling for explanation judgments. ${ }^{4}$ An account of which facts call for explanation must accommodate mathematical facts that call for explanation. To date, no published account does so. In this short essay I explore which common assumptions must be revised to accommodate mathematical facts that call for explanation. I will not develop here a full account of calling for explanation. That I will do elsewhere at greater length.

\footnotetext{
${ }^{3}$ Sometimes the explananda are events rather than facts, sometimes the relevant property is described as "surprise" or "puzzlement", rather than "calling for explanation". For a more nuanced discussion of Horwich, see Baras (2019). For discussion of Schlesinger, see Baras (unpublished ms.).

${ }^{4}$ Prior to this paper, the possibility that necessary truths can call for explanation has been raised in blogposts by Pruss (2013) and Berry (2017), and in Baras (2017a, p. 203) and Baras (2017b, p. 485) in the context of Hartry Field's (1989, pp. 25-30) style of argument against mathematical Platonism and parallel arguments against realisms in other abstract domains. As I completed this paper, Berry developed and published her view in Berry (2020). I engage with this literature and with her article in section 5. In the context of philosophy of mind there is a debate about whether identities, such as mind-body identities, can call for explanation and some have made general claims about necessary facts in this context. Examples are Melnyk (2003, p. 52) and Papineau (2011, p. 9) who claim without much argument that necessary facts cannot call for explanation and Morris (2011, p. 378) who responds by citing mathematical explanations to show that they can call for explanation. These references are all to very brief comments. They do not explore the question in depth as I do here. (I thank Assaf Weksler for referring me to this debate). After completing this paper, I discovered that van Cleve (2018) explores at great length the idea that some necessary facts should be explained. Fortunately, there is not much overlap between the papers, so they nicely complement each other.
} 
Let us look at examples. Suppose you measure the sides of a certain right-angled triangle and notice that the square of the hypotenuse equals the sum of squares of the other two sides. You measure hundreds of other right-angled triangles and learn that this relationship always holds. It seems that if you were in such a position, and were not previously familiar with Pythagoras's theorem, you would surely judge that this result calls for explanation.

A classic example from number theory is the quadratic reciprocity theorem, first proved by Gauss, showing an unexpected relationship that holds between any two arbitrarily chosen odd primes. The intuition that this result is in need of explanation has motivated a continuing search for explanatory proofs, yielding over two hundred proofs to date. Gauss himself devised during the course of his life eight different proofs of the theorem, in search for a more explanatory proof than his initial inductive proof. William D’Alessandro uses this as a fruitful case study for explanation in mathematics, his starting point being that "mathematicians have viewed [quadratic reciprocity] as a remarkable fact that calls out for explanation", a claim he supports with many quotes from mathematicians (D’Alessandro, 2020, sec. 2.3.1). ${ }^{5}$

Examples like this exist in abundance. One rich repository of examples is Marc Lange's work on explanation in mathematics (2016, Chapters 7-9). Lange is not concerned with calling for explanation, but his discussion of what makes certain proofs more explanatory than others is full of examples of mathematical results that give rise to calling for explanation intuitions. This is of course no coincidence. We become interested in looking for explanatory proofs when we come across a result that intuitively calls for explanation. Here is one very simple example:

\footnotetext{
${ }^{5}$ I thank an anonymous referee for this example.
} 
Take an ordinary calculator keyboard (though without the zero):

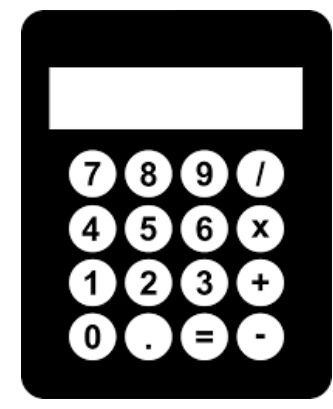

We can form a six-digit number by taking the three digits on any row, column, or main diagonal on the keyboard in forward and then in reverse order. For instance, the bottom row taken from left to right, and then right to left, yields 123321 . There are 16 such “calculator numbers”: 123321, 321123, 456654, 654456, 789987, 987789, 147741, 741147, 258852, 852258, 369963, 963369, 159951, 951159, 357753, and 753357. As you can easily verify (with a calculator!), every one of these numbers is divisible by 37 . Is this (as the title of a recent Mathematical Gazette article asks) a coincidence? (Lange, 2016, p. 276)

My guess is that this result ignites some curiosity within you. (You may want to have a look at the explanation in Lange (ibid) or Nummela (1987)). On the other hand, if I point out to you that $5 * 8,965=44,825$ and $8,563 / 47=182.1914 \ldots$ and a few more arbitrarily chosen mathematical facts, we do not have similar intuitions. These examples demonstrate that there are mathematical 
theorems that call for explanation. While this is old news to mathematicians, the implications for general accounts of calling for explanation have not been explored previously. ${ }^{6}$

If mathematical theorems can call for explanation, then arguably there are facts of logical necessity that call for explanation. For this to follow, I need not assume that all mathematical facts are logically necessary. I can set aside the complicated question of what the precise modal status of mathematical axioms is. ${ }^{7}$ If a certain mathematical result is implied by a set of axioms and rules of deduction, I take it that the fact that the theorem follows from those axioms and rules is a fact of logic. ${ }^{8}$ In all of the examples of mathematical theorems that call for explanation, part of what calls for explanation is that fact of logic, i.e. that the theorem follows from the axioms and rules. Therefore, examples of mathematical facts that call for explanation are also examples of facts of logic that call for explanation.

The claim that facts of logic can call for explanation is incompatible with the claim that low probability is a necessary condition for calling for explanation only if we make a further standard assumption. The standard way of applying the axioms of probability to propositions includes as an axiom that every proposition that represents a logically necessary fact has probability $1 .{ }^{9}$ If we

\footnotetext{
${ }^{6}$ What precisely is a mathematical explanation and how does it stand in relation to other types of explanation? These are difficult questions that I cannot address. I note though that Lange's (2016) account seems attractive. For a classic, see Steiner (1978). For a recent survey, see Mancosu (2018).

${ }^{7}$ For a recent argument for the necessity of mathematics from mathematical practice, see Hawthorne \& Yli-Vakkuri (2018). For doubts about the necessity of mathematics, see Field (1989, Chapter 7).

${ }^{8}$ For a formal argument (unfortunately, not very accessible to non-mathematicians) that mathematical claims can be translated to hypothetical claims in modal logic (S5) about what follows necessarily from certain axioms, see Hellman $(1993,1996)$. I remain neutral with regard to his further claim that this is all that mathematical claims amount to. (I thank Sharon Berry for discussion and the reference to Hellman).

${ }^{9}$ See Hájek (2011, sec. 1), Talbott (2006, sec. supplement) and Strevens (2017, p. 13).
} 
assume accordingly that necessary facts have a high probability, the result is a triad of incompatible claims:

(i) There are truths of classical logic that call for explanation.

(ii) All truths of classical logic have high probability.

(iii) A fact calls for explanation only if it has low prior probability.

Which of these claims should we reject? Or is there some ambiguity here such that the claims are not really inconsistent? This is the dilemma that I wish to explore in this paper. Some dilemmas are hard to solve. In this case I will argue that once we get clearer on what we mean precisely by "calling for explanation" and by "probability", the dilemma is solved. Solving this dilemma is not the only purpose of this paper. (If it were, section 4 would suffice). The dilemma serves also as an excuse to delve more deeply into each of the three claims. As we will see, each of the claims needs refinement.

In the next three sections I explore each of the three principles in turn. Then, in section 5, I discuss an implication. I argue that understanding how necessary facts can call for explanation is important for making progress on assessing reliability arguments against mathematical Platonism and realism about normativity. In particular, I argue that necessary facts call for explanation, but there is little evidence that they do so in the sense needed to block a certain trivializing response to reliability arguments. My conclusions are summarized in the final section. 


\section{What does "calling for explanation" mean?}

What do we mean when we say that some fact calls for explanation? In practice, the term is ambiguous and different people mean different things. ${ }^{10}$ I will now describe four different meanings of the term, the list is not exhaustive, all of which apply to the examples of the contingent facts that call for explanation. We will then consider which of those meanings applies to the mathematical examples.

Sometimes, when people say that a certain fact calls for explanation, or that a certain hypothesis would call for explanation if it were true, people refer to a psychological phenomenon. They mean that a certain fact gives rise to a sense of curiosity or an interest in discovering an explanation for that fact. Let us call this purported fact $E$ (as in explanandum).

(1) Psychological: E gives rise to a feeling of curiosity and interest in discovering what the explanation of $\mathrm{E}$ is.

Normally, there is an epistemic precondition for having such curiosity. The precondition is that at present, given one's background assumptions about the world, (these may or may not constitute knowledge) one does not possess (i.e. justifiably believe) an explanation for the given fact. Let us call this set of background assumptions $A$. Sometimes when people say that a fact calls for explanation, they mean to say that:

(2) Lack explanation: Given a set of background assumptions about the world $A$, we currently lack an explanation for $E$.

\footnotetext{
${ }^{10}$ For examples and some more elaboration, see Baras \& Shenker (2020).
} 
Other times, people mean more than just us lacking an explanation. They mean in addition that we have some special reason to believe that there is in fact an explanation to be found. And by this they mean to exclude the possibility that $E$ is coincidental. ${ }^{11}$ That is, they mean that:

(3) Reason to expect an explanation: Given a set of background assumptions about the world $A$, we have some reason to believe that $E$ has an explanation (perhaps a special kind of explanation). ${ }^{12}$

That means that either the background assumptions imply an explanation that we failed to notice, or there is some further fact to be learned that, together with the background assumptions, will explain the hypothesized fact.

Sometimes, however, people mean something with even stronger epistemic import. They take the fact that some purported fact calls for explanation as a reason to reject certain background assumptions, or else to disbelieve that the purported fact is in fact a fact. When they say that $E$ calls for explanation, they mean that:

(4) Reason to revise beliefs: It is implausible that $E$ is a coincidence (in virtue of a certain property of $E$ ) and therefore, if a set of background assumptions $A$ implies that $E$ is

\footnotetext{
${ }^{11}$ In ordinary conversation, "coincidence" is sometimes used as synonymous with "lacks an explanation". Other times, people use "coincidence" and "explanation" differently, such that a coincidence is considered a legitimate type of explanation. My use of these terms here (and I'm following a core of the literature) is in accordance with the former, not the latter.

${ }^{12}$ There is a theoretical question here, which I will explore elsewhere, whether the claim is just that E must have an explanation, or a stronger claim, that $\mathrm{E}$ must have a particular kind of explanation. For the purposes of this article, the distinction will not matter. For preliminary discussion, see Baras (2019) and Baras (2020).
} 
coincidental, then that is a reason to either disbelieve $A$ or disbelieve that $E$ is the case. $^{13}$

When people say that some fact calls for explanation, they often mean some combination of claims $1-4$. All these claims apply to and can be illustrated by the opening examples for contingent facts that call for explanation. Let us demonstrate using the coin example.

If a coin were to land in a very orderly sequence such as that mentioned above, it would surely make us curious (claim 1). We would be interested in discovering how it is that the coin lands in such an orderly pattern. Part of why we have this sense of curiosity is that, as we imagine the scenario, it would also be the case that we lacked an explanation for these facts (claim 2).

Moreover, a coin landing so many times in such an orderly sequence seems like something that ought to have an explanation. We do seem to have a reason to believe that it has an explanation (claim 3). Finally, we seem to have a reason to reject certain background assumptions that we would have had otherwise had (claim 4). If we originally thought that the coin was an ordinary fair coin and the tosses were independent, we would now suspect that both of these claims are false. Rather, we should think that there is something different about the coin or the tosses such that each toss is bound to land on the opposite side of the previous toss. In this original version of the case, we would be led to reject some of our background assumptions. A variant on the case demonstrates that sometimes, the right response is to disbelieve the purported explanandum rather than any background assumptions. Suppose that instead of directly observing the coin, you were told by another person about the coin. Even if this other person would otherwise be

\footnotetext{
${ }^{13}$ This epistemic principle is sometimes called "the striking principle" because some authors call the property in virtue of which a fact calls for explanation "strikingness". For references to authors who endorse this principle and arguments that rely on it as a premise, see Baras $(2019,2020)$
} 
trustworthy, in this instance we would have a strong reason to doubt the testimony. That is, we should disbelieve that a coin landed in such a sequence.

Now let us see which of these claims applies to the mathematical examples. In what sense does the calculator example call for explanation? You are likely curious about it and interested in learning what the explanation is (claim 1). Assuming you haven't looked at Lange yet, you currently lack an explanation for this phenomenon (claim 2). And, you intuitively believe that there likely is some explanation to be found (claim 3). In these three ways, the mathematical examples are just like the contingent examples. However, the example is not one in which we have some reason to reject the result or some background assumption (not claim 4). Once you become confident that the calculator result holds, there is no salient background assumption that you ought to revise (except for the fact that you did not expect in advance to discover this phenomenon). And if another person would tell you about this result, you would have no special reason to doubt it, at least in comparison with any other mathematical claim that that other person might make and which you have not yet proven or disproven on your own.

It might matter whether necessary facts call for explanation in sense 4 for reliability arguments against mathematical Platonism and similar arguments. I will say more about this shortly, in section Error! Reference source not found.. This does give me reason to pause and consider a bit more closely whether mathematical facts call for explanation in sense 4. I will now raise two reasons to doubt my previous claim.

First, there is a reason to doubt that even in cases like calculator numbers, the mathematical fact really does not call for explanation in the fourth sense. Why is it that mathematical examples of the type discussed do not seem to call for explanation in the fourth sense of putting into doubt 
either the purported facts or the background assumptions? Here is a suggestion. When we come to believe a mathematical fact, it is usually on the basis of a very reliable method, a proof, and therefore once we accept that some mathematical claim is true, for instance, that all calculator numbers are divisible by 37 , it would take a lot to put this belief into doubt. Furthermore, even when we lack an explanation for some mathematical fact, the ordinary situation is that our background assumptions do not rule out the possibility that there is such an explanation. For instance, I cannot think of any background belief that I have that would imply that calculator numbers being divisible by 37 is a coincidence. In addition, our background assumptions about math tend to be assumptions of which we have high credence and strong justificatory support, so it would take a lot to put those into doubt. For these reasons, even if a fact called for explanation in the fourth sense, of giving us reason to doubt the fact or background assumptions, this would typically not have a felt impact on our beliefs.

If this suggestion is correct, it may be more accurate to say that mathematical facts of the kind explored in this paper do give us reason to doubt background assumptions that imply that the facts are coincidental, that is, call for explanation in sense 4, however, the reason is either outweighed or doesn't apply to our beliefs, for the reasons mentioned.

Second, perhaps instead of distinguishing between senses 3 and 4 of calling for explanation, it would be simpler and more accurate to posit the following sense of calling for explanation: ${ }^{14}$

$3^{\prime}$ : There is reason to believe that $\mathrm{E}$ has an explanation.

\footnotetext{
${ }^{14}$ I thank Assaf Weksler for this suggestion.
} 
Whenever E having an explanation is compatible with background assumptions, if E calls for explanation in sense $3^{\prime}$, that implies that it also calls for explanation in sense 3 . On the other hand, whenever E having an explanation is incompatible with background assumptions, 3' implies 4. If this is a better way of understanding ways in which facts can call for explanation, it implies that when mathematical facts of the type explored here call for explanation, they essentially call for explanation in the same ways that contingent facts call for explanation.

In sum, the mathematical examples clearly support the claim that there are truths of classical logic that call for explanation (i), if by calling for explanation we mean some combination of claims 1,2 or 3 , that is, that we are curious, currently lack an explanation and have some reason to believe that there is an explanation. However, if we mean claim 4, that we have reason to disbelieve some background assumption or the explanandum, then it is less clear that mathematical examples of the sort illustrated above support the claim that there are logical truths that call for explanation. ${ }^{15}$

\section{What does probability mean?}

What precisely does it mean to say that facts of logical necessity have probability 1 (ii)? Interpretations of probability can be divided to two main classes: epistemic and objective (Gillies, 2000, p. 2). I will discuss the implications of each in turn. These two categories may not be exhaustive. In the end of this section I will say something about a type of interpretation of probability that may not be reducible to either of the two.

\footnotetext{
${ }^{15}$ Perhaps there are other examples that do support the possibility of mathematical claims calling for explanation in sense (4). Some colleagues have suggested to me that there are arguments against certain mathematical axioms that can be understood as based on the claim that those axioms imply that a mathematical fact that calls for explanation could not be explained. Assessing such proposed examples would require further research.
} 
According to epistemic interpretations, probability functions represent degrees of belief, or credences (or degrees of confirmation or justification), that subjects have (or can have or should have) for sets of propositions. The closer the probability of some proposition is to 1 , the more certain the represented subject is of that proposition. Actual people's beliefs probably never conform to the axioms of probability. One reason is that most of us probably have some inconsistent doxastic attitudes. That is why there is no representation of credences as probability functions without some idealization. ${ }^{16}$ Attributing probability 1 , interpreted as full confidence, to all logically necessary propositions is one such idealization. Since it implies that we are fully confident of every logical truth, it is often called logical omniscience. It is an idealization since people do not even have the capacity to be logically omniscient. One reason is that many logical truths are so complicated that their proof is beyond our cognitive capabilities. Another, is that we are logically fallible, so arguably we should rarely if ever be fully confident in our logical deductions (Schechter, 2013).The question to ask is whether in the context of necessary facts that call for explanation, the idealization is appropriate.

There are at least two types of justifications for idealization involved here. ${ }^{17}$ The first is pragmatic. For instance, probability functions are relatively simple and well understood mathematically. Using them often simplifies matters. The second is normative. When representing credences using probability functions, we typically are not trying to represent what

\footnotetext{
${ }^{16}$ Other adherents of epistemic interpretations add additional constraints for the priors because they believe that not every probability distribution that conforms to the axioms is rational. Such views are often called "logical" interpretations of probability.

${ }^{17}$ I'm inspired here by Colyvan (2013), who distinguishes three types of motivations for idealization in normative domains. Colyvan lists mathematical simplicity as an independent type of motivation whereas I group it with other pragmatic considerations. (I thank Arnon Levy for acquainting me with this discussion).
} 
actual people actually believe. Rather, we represent what actual or hypothetical people ought to believe. For example, even if nobody actually has fully coherent beliefs, using a framework that implies a certain kind of coherence can be fine, given that we ought to, or, would be epistemically better off (other things being equal (which is never the case)), if our beliefs were coherent. Both types of justification suggest that sometimes, certain idealizations lose their justification.

Attempts to model epistemic probability without logical omniscience demonstrate that without this idealization the task of modeling gets very complex and difficult. ${ }^{18}$ Hence, there are pragmatic benefits to this idealization. However, the fact that the idealization makes things simpler does not make it accurate. When we are interested in what actual people believe, we must take into account that they are not logically omniscient. And when we are interested in what they ought to believe, we must take into account that people do not even have the capacity to be logically omniscient.

Similarly, normative justifications for idealization have their limits. When modeling what we ought to believe, in contrast to what we actually believe, different levels of idealization are possible because there are many ways in which our beliefs can be better than they actually are. And I suggest that correspondingly, there are many senses of epistemic ought. Our beliefs would be better if they were actually all true. I suggest that this permits us to say that, in a sense, our beliefs ought to be all true. Our interests can determine how far we are willing to depart from our actual beliefs and capacities in a given context. Our beliefs would be better if they were fully

\footnotetext{
${ }^{18}$ For an attempt to develop a formal representation of credences without logical omniscience, see Gaifman (2004). Bjerring (2013) demonstrates difficulties in using an impossible worlds framework for this task.
} 
coherent. I suggest that this permits us to say that in a sense, we ought to have fully coherent beliefs. And so on. It is therefore correct to say that, in a sense, our beliefs ought to be logically consistent. It therefore makes normative sense as well to build in the idealization of logical omniscience into a formal epistemological framework, i.e. the Bayesian framework. ${ }^{19}$ However, even if we strive to be logically omniscient, we must keep in mind that we do not have the capacity to be such. This is true especially when we are theorizing about our beliefs in a domain of necessary truths. In such a context, the logical omniscience idealization is less appropriate, even from a normative perspective.

If we understand probability as epistemic probability, then the claim that (ii) truths of classical logic have probability 1 is an idealization that should be given up in some contexts. That is because we often, in a sense, should have less than full confidence in logical facts. And we can even, in a sense, be justified in having low credence. Prior to reading Lange or calculating, if you would have asked me how confident I am that all calculator numbers are divisible by 37, I would have said not in the least (=very low). And it seems that, at least in a sense, that is how I should respond. One should not be confident that calculator numbers are divisible by 37 without calculating or receiving reliable testimony for that claim.

If by probability we mean objective probability, then it is difficult to reject the claim that (ii) truths of classical logic have probability 1 . According to objective interpretations, probabilities are some sort of mind-independent facts of the world. Precisely which facts, and whether it is even reasonable to attribute such facts to our world, are very difficult questions to answer. It does

\footnotetext{
${ }^{19}$ For a defense of accepting the logical omniscience idealization as a normative idealization without global fact omniscience, see Christensen (2004, pp. 153-157) and Smithies (2015).
} 
seem plausible however that logical truths, truths that could not have been false in a very broad sense of could, should be understood as having probability 1 . This is implied by all existing objective interpretations of probability. Whether you think of objective probability as a representation of an actual or hypothetical frequency, or of a propensity of some kind, logical truths never fail even in hypothetical scenarios, and therefore must be of objective probability 1.

There may be a third category of interpretations of probability (Hájek, 2011, sec. 3). Some think of probability as a measure of objective evidential support conceived as existing in abstraction from any actual or hypothetical belief. If we conceive of probability in this way, then we should accept the claim that every logical truth receives probability 1 . It would be inappropriate to call this an idealization of logical omniscience because according to this interpretation, probability is not directly linked to what any person knows or rightly believes. According to this conception, probability is a kind of logical relation, and therefore logical relations should be built in. This interpretation is close in some ways to epistemic interpretations, since evidential support plays a dominant role in determining what we should believe or what we know. However, in another way it is closer to objective interpretations, as it is not an attempt to model something about us, unideal creatures that we are. Therefore, in the context of assigning probability 1 to logical truths, this possible third type of interpretation falls in with the objective interpretation.

In sum, whether we should or should not accept the claim that (ii) truths of classical logic have probability 1 depends on what we mean by probability. I argued that if we interpret probability epistemically then (ii) should be given up. Not in general, but rather in specific contexts like that of analyzing necessary facts that call for explanation. If on the other hand we mean by probability something independent of what we do or should believe, then we should accept (ii). 


\section{$4 \quad$ Is low prior probability necessary for calling for explanation?}

Whether we interpret probability epistemically or objectively, I believe that we should reject the claim that low probability is a necessary condition for calling for explanation (iii) in all the mentioned senses of calling for explanation. Although in this paper my discussion of (iii) is motivated by cases of necessary facts that call for explanation, we can argue against (iii) using contingent examples as well.

Let us begin with objective probability. Facts with high objective probability can call for explanation in all four senses of call for explanation. Take the coin example for instance. In the scenario, for all that you know, it may be the case that the coin has very high objective probability of landing in that particular sequence. It might be a special coin tossed in a special way such that objectively, it cannot but land in that sequence. However, given that we do not know this, the coin tosses call for explanation in all four senses. It gives rise to curiosity; we lack an explanation; we would suspect that there is an explanation; and we should reject the prior belief that the coin is ordinary and the tosses independent.

Now let us consider epistemic probability. Facts with high epistemic probability can also call for explanation. Suppose you have been tossing the coin for quite some time now. What should your degree of confidence be that it will continue landing HTHTHTHT...? By now, it should be quite high. This in no way diminishes the fact that the coin tosses call, and will continue calling, for explanation in all four senses. Here is another example. Suppose before tossing the coin, a trustworthy friend tells you that the coin you are about to toss is such that it always lands on the opposite side of the previous toss. Now you should expect it to land in the alternating sequence. And if the probability of a proposition just means the degree to which you should expect it to be 
true, as epistemic interpretations say, then prior to tossing the coin the probability of it landing HTHT... will be high. Nevertheless, after it is tossed it will call for explanation no less.

Of course, a key question is, when we talk about low prior probability, what precisely do we mean? Prior to what? My analysis of the coin examples assumes that it means the probability of a proposition prior to learning that it is true. In the first case, it is the probability that the coin will continue landing HTHT... after I have tossed the coin several times but before I continue tossing it. In the second case, it is the probability of it landing HTHT after receiving a trustworthy testimony. You may suggest that there is an alternative analysis of these examples that does not imply that a fact with high prior probability can call for explanation. The alternative says that the relevant probability function is the one at an even earlier time, prior to having tossed the coin at all or hearing any testimony. However, the question just becomes starker. Why should it matter what I should have expected a while back, to whether a fact calls for explanation? My expectations at an earlier time seem irrelevant, and the choice of the relevant earlier time seems unprincipled and ad hoc as well.

A final suggestion is that prior probability should not be interpreted temporally, but rather, it is a matter of what our theories, the theories we justifiably believe, predict, setting aside additional information about the occurrence. ${ }^{20}$ In the coin example, the theory is supposed to be that the coin is fair. Once we set aside information about how the coin landed or how exactly it was tossed, the fair-coin theory predicts that all sequences are equiprobable, and therefore have low probability. I do not believe this proposal succeeds. In the testimony example, our theory regarding the coin should not be that the coin is fair. In fact, we should be confident that the

\footnotetext{
${ }^{20}$ I thank Jessica Wilson for raising a suggestion along these lines in conversation.
} 
correct theory, whatever it is, predicts the alternating sequence. In addition, this suggestion will not help with mathematical examples where all mathematical theorems, whether they call for explanation or not, are implied by the axioms.

From all these considerations, that is, mathematical facts that call for explanation and expected contingent facts that call for explanation, and the seeming irrelevance of expectations at a previous time, I conclude that low prior probability is not a necessary condition for calling for explanation.

You may wonder at this point, why then did (iii) seem compelling to begin with? How did it come to be that a thoughtful philosopher pronounces that "no one disputes the necessity of this condition" (Mogensen, n.d., n. 24)? I suggest that we were initially confused because, although low probability is not a necessary condition for calling for explanation, there typically is a close connection between calling for explanation and low probability interpreted epistemically. A fact with low epistemic prior probability is just a fact that we should not have predicted, given our prior evidence. Now there is a close connection between being able to explain and being able to predict such that if I don't possess an explanation for some explanandum $e$ then it will also typically be the case that I could not predict $e$. Likewise with the converse. Typically, I can predict some $e$ for the same reason that I can explain $e$ once it occurs. If I know that a certain die is weighted towards landing six, then I can predict that it will land six on most tosses. It is no coincidence that after tossing the die and observing that it lands six most of the times, I possess an explanation for the occurrence. Still, explanation and prediction are not fully correlated. Whether we can possess an explanation for $e$ without being able to predict $e$ is a controversial and complex issue. However, it is uncontroversial that there are facts that we can predict without being able to explain them. For instance, if we discover a correlation between two variables, we 
can then predict one variable based on the other, despite a lack of an explanation for the correlation. Correlation, as we all know, does not imply causation, nor does it imply explanation. Or to take a simpler example, suppose a trustworthy witness tells you that in the next room there is a coin that always lands in the alternating sequence HTHTHT... (when tossed more than once). You should then expect the coin to land in this sequence, but it would call for explanation none the less.

Often one finds in the literature that the notions of "calling for explanation" and "surprise" are confused, as if they mean the same thing. ${ }^{21}$ I suggest that this mistake has also misled intuitions about calling for explanation. That is because part of what makes an occurrence surprising is that it was unexpected. And this includes mathematical facts such as the calculator phenomenon. The fact that all calculator numbers are divisible by 37 is surprising in part because we would not have expected this to be the case prior to having been told or discovered by calculation that it is the case. However, surprise and calling for explanation are distinct notions. Being unexpected is a necessary condition for surprise, but not for calling for explanation.

In sum, there is some correlation between having high epistemic probability, i.e. being expected, and not calling for explanation. That is why it seemed initially appealing to hypothesize that low probability is a necessary condition for calling for explanation (iii). However, as we have seen, this hypothesis fails upon examination.

\footnotetext{
${ }^{21}$ See Baras (2019, sec. 4) for some discussion.
} 


\section{$5 \quad$ Implications for reliability arguments}

The above results will help us make progress in understanding which facts call for explanation and why, a theoretical project interesting in its own right. But they also play an important role in determining specific applications of calling-for-explanation reasoning. In this section I explain how the insights of this article can help us make progress in assessing Hartry Field's (1989, pp. 25-30) influential reliability argument against mathematical Platonism. Field argues that "the correlation between mathematicians' belief states and the mathematical facts...is so striking as to demand an explanation" and he further argues that there are principled reasons to believe that Platonism deprives us of the possibility of such an explanation. This, Field argues, is a significant reason to reject Platonism. More recently it has been recognized that Field's argument, if sound, generalizes to Platonism, or robust realism as the view is more often called these days, about other domains, such as normativity (Enoch, 2011, Chapter 7; Street, 2016) and logic (Schechter, 2010, 2018).

To be sure, Field's style of argument, premised on the idea that some facts call for explanation in the relevant sense, is not the only epistemological argument against robust realist theories in abstract domains. Field himself was offering an improved version of Benacerraf's (1973) variant, and other theorists have offered yet other versions, that do not rely on the calling for explanation idea. However, Field's version is thought by many to have significant advantages over the others. Sharon Berry voices a shared sentiment that "unlike Benacerraf's original access worry, Field's formulation does not depend on any contentious assumptions about causal constraints on knowledge" (Berry, 2020). To this I add that it also does not depend, at least not in an obvious way, on modal conditions such as safety or sensitivity, which might be too easy to satisfy in the case of necessary truths, as Justin Clarke-Doane (2020, Chapter 4) argues. Similarly, David 
Enoch argues at length that Field's style of argument is the best way to formulate the epistemological challenge for robust realism about normativity (Enoch, 2011, Chapter 7).

One popular kind of response to Field's style of argument, sometimes called the trivializing response (Berry, 2020), runs along the following lines. What the robust realist must explain, it is argued, can be formulated as the following conjunction

The set $\mathrm{S}$ of mathematical claims are true $\&$ mathematicians believe $\mathrm{S}$.

Then it is argued that the first conjunct does not require explanation, because necessary facts cannot call for explanation. Therefore, all that needs explaining is the second conjunct. The second conjunct, however, can in principle be explained by citing all the historical factors that led mathematicians to adopt their current beliefs. If the conjuncts are individually explained, then, some have argued, the conjunction is explained as well. Alternatively, if the conjunction is showed to be highly probable, because each of the conjuncts is highly probable, then it is thought to no longer call for explanation. Such moves are suggested, for instance, by Burgess and Rosen (1999, pp. 41-46), Pust (2004), Clarke-Doane (2016) and Baras (2017a). In ethics, a similar move has been defended by Enoch (2011, Chapter 7) and Weilenberg (2010) among others. ${ }^{22}$ In response to the trivializing response, anti-Platonists have used examples from mathematics of the kind discussed in this paper to question the supposition that necessary facts cannot call for explanation. The most recent and explicit example is Sharon Berry, who uses an example to demonstrate that we have intuitions about mathematical results that call for explanation.

\footnotetext{
${ }^{22}$ Recent critiques of this style of response include Schechter (2018), Faraci (2019) and Korman and Locke (forthcoming).
} 
The history of John Conway's "Monstrous Moonshine" conjecture ... shows how discovering a relationship between pure mathematical facts which intuitively "cries out for explanation," and, then, seeking such an explanation can lead to important discoveries even when a proof of both facts already exists. In this episode, mathematicians noticed that the same number-196,883 - appeared in two seemingly unconnected areas of mathematics. It appeared both as one of the dimensions of the monster group (the largest of the sporadic simple groups) and as the first nontrivial coefficient of the j-function (an important function in number theory). Later mathematicians discovered further that the second nontrivial coefficient of the $\mathrm{j}$-function was the sum of the first three special dimensions of the monster group...the fact that these coincidences seemed to call out for explanation motivated mathematicians to hypothesize a connection and eventually discover one which lead to deep mathematical insights. (Berry, 2020)

She argues on this basis against trivializing responses to Field's argument. The results of our discussion provide us with new means to analyze Berry's argument, and to make progress in this debate. In one way, our results complement Berry's argument. Berry relies on the intuition that mathematical facts can call for explanation without exploring what impact this might have on general accounts of which facts call for explanation. She neither attempts to propose such an account, nor engages with existing ones. Here we argued that previous accounts fail, because they posit low prior probability as a necessary condition for calling for explanation. We further bolstered this claim using examples of contingent facts that call for explanation.

However, in another way, this paper exposes a weakness in her argument. As explained in section 2, "calls for explanation" can mean more than one thing, and it is important to keep the various meanings apart. What her example shows is that a certain mathematical fact motivated a 
certain fruitful research project, to find a mathematical explanation for a striking result. Calling for explanation here is used in sense 3, it means having reason to believe of a certain fact that it has an explanation. However, this is not the kind of example we need in order to defend Field's argument from trivializing responses. The sense of calling for explanation that Field needs is sense 4, according to which we should revise beliefs that imply that a certain fact is coincidental. Our discussion at the end of section 2 applies to Berry's example as well. Her example fails to show that mathematical facts call for explanation in the sense needed to support the reliability argument against mathematical Platonism.

\section{Conclusion}

We started with an incompatible triad of claims. By reflecting more deeply upon these claims, the seeming paradox has dissolved. We can now look again at the inconsistent triad and sum up what we have learned:

(i) There are truths of classical logic that call for explanation.

(ii) All truths of classical logic have high probability.

(iii) A fact calls for explanation only if it has low prior probability.

The first claim is ambiguous, depending on what is meant by "call for explanation". According to one interpretation, it is not so clearly supported by mathematical examples of the kind given above. The second claim is also ambiguous, depending on what is meant by "probability". On some interpretations it is an idealization that should be dropped in some contexts. The third claim, as it stands, is false. There is however a nearby truth, which is that in many cases, facts that call for explanation are also, non-coincidently, highly improbable. In addition, there is a 
sense in which low probability is a necessary condition for surprise to be fitting, and surprise is often conflated with calling for explanation.

\section{Acknowledgements}

I am thankful to Sharon Berry, David Enoch, Arnon Levy, Alexander Pruss, Joshua Schechter, Assaf Weksler, two anonymous reviewers and to the audiences at my presentations at the $22^{\text {nd }}$ Israeli Philosophical Association conference (2019) and the $93^{\text {rd }}$ Joint Session of the Aristotelean Society and the Mind Association (2019) for very helpful comments and discussion.

\section{$\underline{\text { References }}$}

Baras, D. (n.d.). Calling for Explanation: An Extraordinary Account (unpublished ms.). Retrieved April 18, 2019, from https://www.academia.edu/38849164/Calling_for_Explanation_An_Extraordinary_Account

Baras, D. (2017a). Our Reliability is in Principle Explainable. Episteme, 14(02), 197-211. https://doi.org/10.1017/epi.2016.5

Baras, D. (2017b). A reliability challenge to theistic Platonism. Analysis, 77(3), 479-487. https://doi.org/10.1093/analys/anx089

Baras, D. (2019). Why Do Certain States of Affairs Call Out for Explanation? A Critique of Two Horwichian Accounts. Philosophia, 47(5), 1405-1419. https://doi.org/10.1007/s11406-0180047-X 
Baras, D. (2020). A strike against a striking principle. Philosophical Studies, 177(6), 1501-1514. https://doi.org/10.1007/s11098-019-01265-5

Baras, D., \& Shenker, O. (2020). Calling for Explanation: The Case of the Thermodynamic Past State. European Journal for Philosophy of Science. https://doi.org/10.1007/s13194-02000297-7

Benacerraf, P. (1973). Mathematical Truth. The Journal of Philosophy, 70(19), 661-679. https://doi.org/10.2307/2025075

Berry, S. (2017). Trivializing Benacerraf and Monstrous Moonshine. http://philosophyinprogress.blogspot.co.il/2017/10/trivializing-benacerraf-andmonstrous.html

Berry, S. (2020). Coincidence Avoidance and Formulating the Access Problem. Canadian Journal of Philosophy. https://doi.org/10.1017/can.2020.15

Bjerring, J. C. (2013). Impossible worlds and logical omniscience: An impossibility result. Synthese, 190(13), 2505-2524. https://doi.org/10.1007/s11229-011-0038-y

Burgess, J. P., \& Rosen, G. (1999). A Subject With No Object. Oxford University Press. https://doi.org/10.1093/0198250126.001.0001

Christensen, D. (2004). Putting Logic in its Place. Oxford University Press. https://doi.org/10.1093/0199263256.001.0001

Clarke-Doane, J. (2016). What Is the Benacerraf Problem? In F. Pataut (Ed.), New Perspectives on the Philosophy of Paul Benacerraf: Truth, Objects, Infinity (pp. 17-43). Springer. https://doi.org/10.1007/978-3-319-45980-6_2 
Clarke-Doane, J. (2020). Morality and Mathematics. Oxford University Press.

Colyvan, M. (2013). Idealisations in normative models. Synthese, 190(8), 1337-1350. https://doi.org/10.1007/s11229-012-0166-Z

D'Alessandro, W. (2020). Proving quadratic reciprocity: explanation, disagreement, transparency and depth. Synthese. https://doi.org/10.1007/s11229-020-02591-6

Enoch, D. (2011). Taking Morality Seriously. Oxford University Press. https://doi.org/10.1093/acprof:oso/9780199579969.001.0001

Faraci, D. (2019). Groundwork for an Explanationist Account of Epistemic Coincidence. Philosophers 'Imprint, 19(4), 1-26.

Field, H. (1989). Realism, Mathematics, and Modality. Basil Blackwell.

Gaifman, H. (2004). Reasoning with limited resources and assigning probabilities to arithmetical statements. Synthese, 140(1-2), 97-119. https://doi.org/10.1023/B:SYNT.0000029944.99888.a7

Gillies, D. (2000). Philosophical Theories of Probability. Routledge.

Hájek, A. (2011). Interpretations of Probability. In E. N. Zalta (Ed.), Stanford Encyclopedia of Philosophy.

Harker, D. (2012). A surprise for Horwich (and some advocates of the fine-tuning argument (which does not include Horwich (as far as I know))). Philosophical Studies, 161(2), 247261. https://doi.org/10.1007/s11098-011-9732-3

Hellman, G. (1993). Mathematics without Numbers. Oxford University Press. 
https://doi.org/10.1093/0198240341.001.0001

Hellman, G. (1996). Structuralism Without Structures. Philosophia Mathematica, 4(2), 100-123. https://doi.org/10.1093/philmat/4.2.100

Horwich, P. (1982). Probability and Evidence. Cambridge University Press.

Korman, D. Z., \& Locke, D. (n.d.). Against Minimalist Responses to Moral Debunking Arguments. In Oxford Studies in Metaethics.

Lange, M. (2016). Because Without Cause. Oxford University Press. https://doi.org/10.1093/acprof:oso/9780190269487.001.0001

Leslie, J. (1989). Universes. Routledge.

Mancosu, P. (2018). Explanation in Mathematics. In E. N. Zalta (Ed.), Stanford Encyclopedia of Philosophy.

Manson, N. A., \& Thrush, M. J. (2003). Fine-Tuning, Multiple Universes, and the This Universe Objection. Pacific Philosophical Quarterly, 84, 67-83. https://doi.org/10.1111/14680114.00163

Melnyk, A. (2003). A Physicalist Manifesto. Cambridge University Press. https://doi.org/10.1017/CBO9780511498817

Mogensen, A. L. (n.d.). Ethics, Evolution, and the Coincidence Problem: a Skeptical Appraisal. Retrieved May 20, 2020, from https://www.andreasmogensen.com/publications-all

Morris, K. (2011). Theoretical Identities as Explanantia and Explananda. American Philosophical Quarterly, 48(4), 373-385. 
Nummela, E. (1987). No coincidence. The Mathematical Gazette, 71(456), 147.

https://doi.org/DOI: 10.2307/3616509

Papineau, D. (2011). What Exactly is the Explanatory Gap? Philosophia, 39(1), 5-19. https://doi.org/10.1007/s11406-010-9273-6

Price, H. (2002). Boltzmann's Time Bomb. The British Journal for the Philosophy of Science, 53(1), 83-119. https://doi.org/10.1093/bjps/53.1.83

Pruss, A. R. (2013). Necessary coincidences. http://alexanderpruss.blogspot.co.il/2013/11/necessary-coincidences.html

Pust, J. (2004). On Explaining Knowledge of Necessity. Dialectica, 58(1), 71-87. https://doi.org/10.1111/j.1746-8361.2004.tb00292.x

Schechter, J. (2010). The Reliability Challenge and the Epistemology of Logic. Philosophical Perspectives, 24(1), 437-464. https://doi.org/10.1111/j.1520-8583.2010.00199.x

Schechter, J. (2013). Rational Self-Doubt and the Failure of Closure. Philosophical Studies, 163(2), 429-452. https://doi.org/10.1007/s11098-011-9823-1

Schechter, J. (2018). Is There a Reliability Challenge for Logic? Philosophical Issues, 28(1), 325-347. https://doi.org/10.1111/phis.12128

Schlesinger, G. N. (1991). The Sweep of Probability. University of Notre Dame Press.

Smithies, D. (2015). Ideal rationality and logical omniscience. Synthese, 192(9), 2769-2793. https://doi.org/10.1007/s11229-015-0735-z

Smolin, L. (1997). The Life of the Cosmos. Oxford University Press. 
Steiner, M. (1978). Mathematical explanation. Philosophical Studies, 34(2), 135-151. https://doi.org/10.1007/BF00354494

Street, S. (2016). Objectivity and Truth: You'd Better Rethink It. In R. Shafer-Landau (Ed.), Oxford Studies in Metaethics (Vol. 11, pp. 293-334). Oxford University Press. https://doi.org/10.1093/acprof:oso/9780198784647.003.0012

Strevens, M. (2017). Notes on Bayesian Confirmation Theory. http://www.nyu.edu/classes/strevens/BCT/BCT.pdf

Talbott, W. J. (2006). Bayesian Epistemology. In Stanford Encyclopedia of Philosophy.

Van Cleve, J. (2018). Brute necessity. Philosophy Compass, 13(9), e12516. https://doi.org/10.1111/phc3.12516

White, R. (2005). Explanation as a Guide to Induction. Philosophers' Imprint, 5(2), 1-29.

White, R. (2018). The Argument from Cosmological Fine-Tuning. In G. Rosen, A. Byrne, J. Cohen, S. V. Shiffrin, \& E. Harman (Eds.), The Norton Introduction to Philosophy (2nd ed., pp. 29-35). Norton.

Wielenberg, E. J. (2010). On the Evolutionary Debunking of Morality. Ethics, 120(3), 441-464. https://doi.org/10.1086/652292

Yli-Vakkuri, J., \& Hawthorne, J. (2018). The Necessity of Mathematics. Nô̂s. https://doi.org/10.1111/nous.12268 